\title{
Directed positioning of single cells in $\mu$-wells fabricated by scanning probe lithography and wet etching methods
}

Inhee Choi, Young In Yang, Yun-Jung Kim, Younghun Kim ${ }^{\mathrm{a}}$, Ji-Sook Hahn, Kyunghee Choi ${ }^{\mathrm{b}}$ and Jongheop $\mathrm{Yi}^{*}$

\section{Supplementary Data}

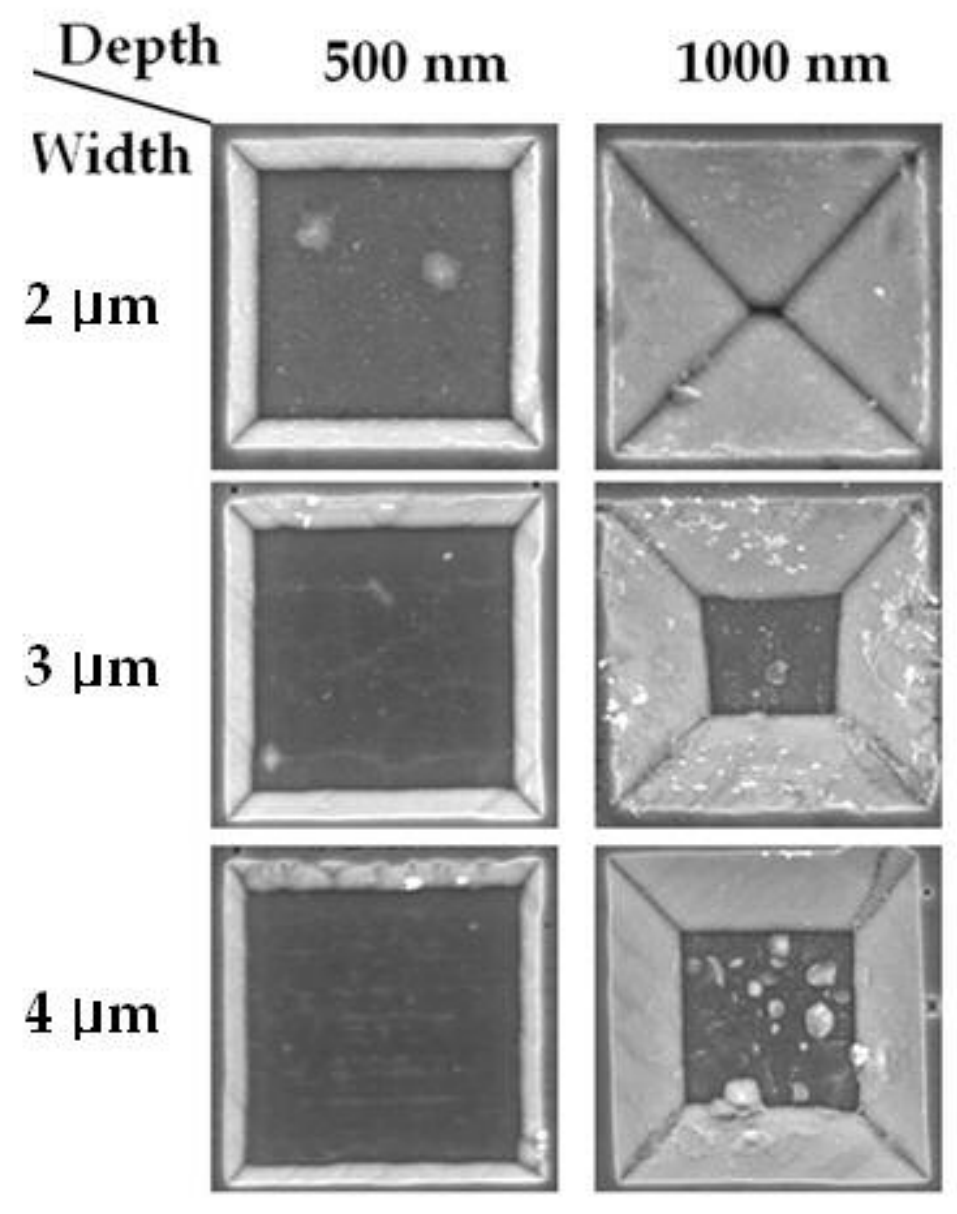

S1. SEM micrographs of individual wells with a variety of geometries corresponding to the AFM topographies of Figure 4, they were obtained after piranha treatment of used $\mu$-well structures in cellcapturing experiment to test reusability.

\footnotetext{
* To whom correspondence should be addressed.
}

E-mail: jyi@snu.ac.kr 